Article

\title{
T'imani a Multifunctional Solar System to Provide Cooking and Water Heating Rural Energy Needs
}

\author{
José Ángel Rodríguez Morales ${ }^{1}$, Mauricio González-Avilés ${ }^{1, *}$, Hermelinda Servín Campuzano ${ }^{1}$ \\ and Omar Masera ${ }^{2}$ (D) \\ 1 Maestría en Ingeniería para la Sostenibilidad Energética, Universidad Intercultural Indígena de Michoacán, \\ Carretera Páztcuaro Huecorio SN KM3 Pátzcuaro, Michoacán CP 61614, Mexico; \\ angel.rodriguez@uiim.edu.mx (J.Á.R.M.); shermelinda@uiim.edu.mx (H.S.C.) \\ 2 Grupo de Innovación en Ecotecnología y Bioenergía (GIEB), Instituto de Investigaciones en Ecosistemas y \\ Sustentabilidad (IIES), Universidad Nacional Autónoma de México (UNAM), Morelia, Michoacán CP 58190, \\ Mexico; omasera@gmail.com \\ * Correspondence: mauricio.gonzalez@uiim.edu.mx
}

Received: 12 May 2020; Accepted: 29 June 2020; Published: 3 July 2020

check for updates

\begin{abstract}
This study describes the development of a multifunctional solar system designed for implementation in some communities in the Meseta Purepecha, Michoacan, Mexico. The multifunctional solar system device — called T'imani (in the Purepecha language) — consists of two modules designed for domestic use: one for cooking food, the other for heating water. The thermal characterization is based on the use of standardized tests for both modules. The parameters obtained indicate that use device is suitable for in the conditions of solar resources in this region. Additionally, a pilot test was carried out to implement some devices that show favorable preliminary results for domestic use. Hence, due to the device functionality and that in Mexico there is abundant solar resources it is feasible to implement the device in many places throughout the country.
\end{abstract}

Keywords: multifunctional solar system; design; thermal parameters

\section{Introduction}

The use of fossil fuels produces (high levels) large greenhouse gases (GHG) emissions, leading to environmental, social and economic impacts [1]. Firewood use exacerbates forest degradation in specific regions and represents approximately $50 \%$ total annual extractions of wood worldwide (3000 million $\left.\mathrm{m}^{3}\right)$ [2].

In Mexico, thermal energy represented $73 \%$ of the total residential energy use in 2015 with electricity consumption accounting for the remaining $27 \%$. Of the thermal energy consumed, $72.8 \%$ was used for cooking food and $27.2 \%$ was used for heating water. The use of firewood represented $33.7 \%$ of total energy consumption in the residential sector, second only to liquefied petroleum gas (LPG) [3]. Approximately 25\% of homes (27.2 million people) cook with firewood [4] and it is estimated that rural communities extract around 28 million $\mathrm{m}^{3}$ of firewood for use as fuel [5]. Firewood is mostly used in open fires, often gathered by women and children, but some families need to purchase it. This expenditure may represent as much as $15 \%-20 \%$ of total household income [4]. Most people that depend on firewood live in the central and southern areas of the country, which coincide with the zones of greatest poverty and margination [1]. The Purepecha region of Michoacan is one of the areas that depend primarily on firewood as an energy resource [6]. Therefore, solar cookstoves and water heaters represent an option to help solve existing domestic energy problems within the region.

In several places around the world, projects have been carried out with the aim of developing alternatives that could help alleviate household energy problems within marginal and rural 
areas-including the high dependence on firewood for cooking and water heating. Solar cookers have been seen as a solution to reduce firewood use for cooking in developing countries. Currently, around half a million solar cookers in the world are used in China alone [7]. Solar Cookers International (SCI) is an organization that began to promote the use of solar cooking in the late 1980s. To date, it has carried out various projects to implement these devices in extremely marginalized zones of Africa and specific regions in Asia [8]. In Latin America, solar cookers have been implemented in Bolivia, Chile, Peru, Argentina and Mexico [9-12]. Regrettably, most of these projects focus on installing the devices without any or little follow-up or monitoring activities, which impacts negatively in their long-term adoption.

These problems have led US government officials and representatives of the Global Alliance for Clean Cookstoves to claim that solar cooking cannot be considered a viable clean technology until its usefulness and acceptance is demonstrated in large-scale projects [13]. However, while some reasons are known why this type of system has not had a positive impact (cost-efficiency ratio), there are no elements to affirm that it is not an appropriate technology. In fact, in some places these systems play an important role in saving energy in where others fuels are not available, such as in Tibet for example [7]. The study of cookstove adoption processes may help solve these problems allowing understanding which role solar cookers may actually play within rural cooking energy systems.

We are group of scientists who have been working in the State of Michoacan, Mexico [14], on the participatory development of solar stoves and other devices for almost a decade [14-16]. The projects change according to the needs of the users-without neglecting the scientific state of the art. Specifically in this study we present the development of a multifunctional solar system (MFSS) designed for passive use that is destined to simultaneously satisfy the needs of domestic energy to cook and heat water in innovative, clean, economic and safe way. If the water storage tank is filled in the morning once the sun is up, it will be ready to be emptied by the afternoon. Estimates indicate that the hot water produced is sufficient for 3 or 4 showers, depending on the hours of daily sunlight. Meanwhile, the food to be cooked can be placed in the absorbing pot before leaving for work and the meal will be hot and ready to eat by midday. Foods that can be cooked include soup, pasta, spinach, mushrooms, meat, gruel, rice, lentils and beans. This cooker can also boil milk, cook eggs and potatoes, etc. It may be that similar devices exist in other parts of the world, but we did not find many implementations of this nature in the review we carried out. In the review we found a water heater that also cooked food, but not simultaneously [17].

The device design is unique and characterized by the application of composite parabolic concentrators (CPCs) as solar collectors. The device was designed according to the needs of local users a method for placing Stove Use Monitors (SUMs) was developed to examine device use through time. Globally, there are few experiences that monitor the use of solar cookers to analyze the adoption process using objective indicators such as SUMs. In some cases, researchers have used similar measurement techniques [18], but have involved expensive instruments that are invasive for users and therefore unsuitable for the present case. SUMs were used to monitor the use of solar cookers in Nicaragua, where the registered patterns provide some indications of their use but offer little certainty about the scope of their use or the purposes for which people use those [19].

Finally, a pilot test was carried out in three communities (Huecato, Santo Tomás and Carapan) placing SUMs in the multifunctional solar systems (MFSS devices).

\section{Materials and Methods}

\subsection{Design and Construction}

The MFSS—called T'imani, in the Purepecha language—-tested performs a dual function because it combines the features of a solar radiation collector that utilizes a revolving compound parabolic concentrator (CPC) and a CPC channel. This type of concentrator offers users safe operation because it employs anidolic-i.e., unfocused—optics to prevent flashes that can damage people's eyesight [20,21]. 
The device was designed by computer-aided software (Figure 1a). In order to optimize the choice and functionality of the geometry devise, solar radiation and the system's operating design, software tools were used.

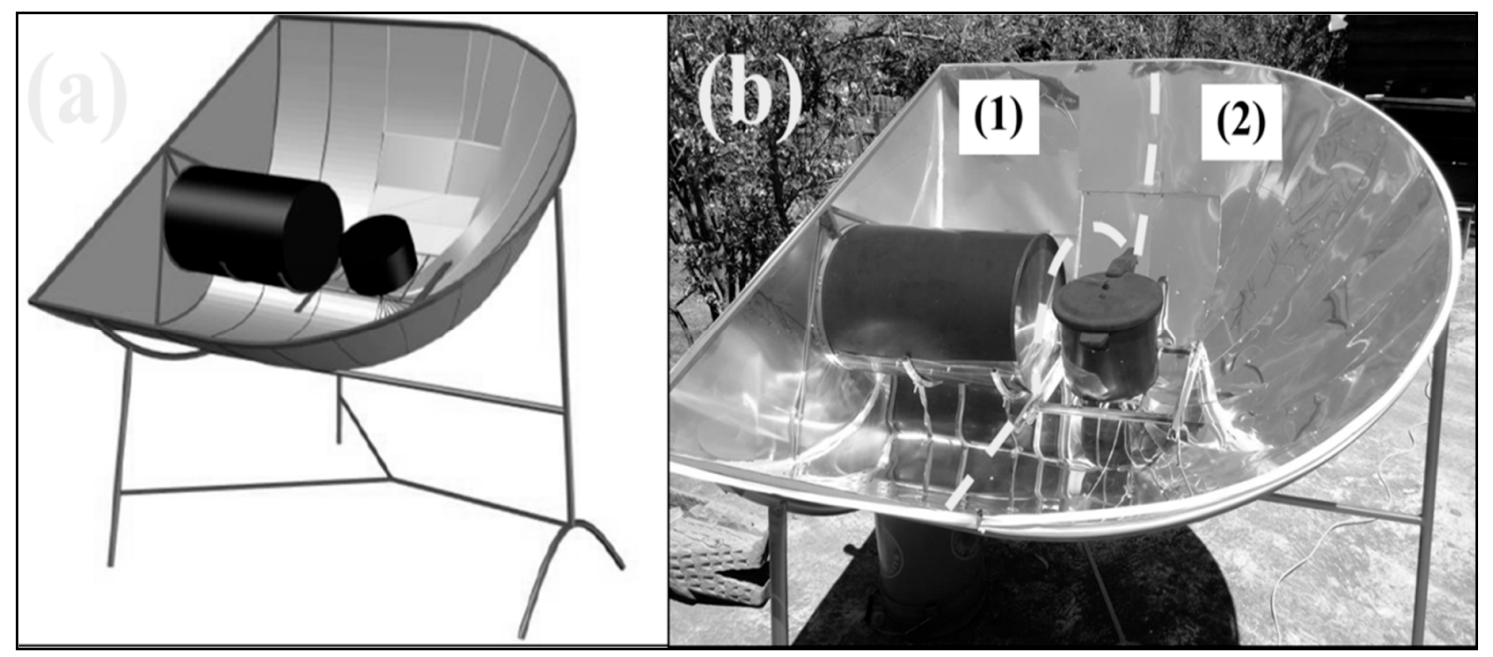

Figure 1. (a) Computer-assisted design of the MFSS; (b) fully-constructed MFSS.

System construction is shown in Figure 1:

- Metallic structure with reflective surface that forms the CPC: a frame made of 40-calibre polystyrene that serves as the base. It has a self-adhering, mirror-type silver-chrome vinyl film placed over a carbon-steel structure and a transparent glass cover placed over the structure to prevent heat loss due to convection.

- Heating tank and water storage tank: a 27-liter metallic recipient the outside of which is painted with a coating of absorbent forest-biomass soot [21] and then wrapped in absorbent sheeting optimized for the rest of the recipient.

- Cooking pot: a pressure cooker made of aluminum and painted black with the same soot-based coating (6-liter capacity).

- Hatch to access the cooking pot: allows access to the recipient where the food to be cooked is placed.

- Glass cover: a 6-mm-thick glass lid that covers the apparatus so that no airflow can enter or escape.

- Concentrator base: a carbon-steel structure that supports the collector.

The collector system is divided into two sections:

(1) Water-heating module (Figure 1(b-1)) made up of the compound parabolic channel and a flat wall with reflectors; the water storage tank with its inlet and outlet; and the support structure for the tank.

(2) Food-cooking module (Figure 1(b-2)) showing the revolving CPC (3D) with solar reflectors, the pressure cooking pot and soot coating.

\subsection{Thermal Characterization of The Device}

The thermal performance $(\eta)$ is defined as the energy gained by the device, divided between the solar energy received. Energy received refers to the amount of energy that enters through the collector's incident plane per unit area; that is, capture area and the integrated radiation that enters the device during the time of the experimentation. The energy gained by the device " $\mathrm{T}$ 'imani" is based on the temperature changes of the water $\left(T_{w}, T_{a}\right)$ and solar radiation in each time interval. 
The temperatures and solar radiation are recorded every $5 \mathrm{~min}$ in a data sheet where they are later manipulated. Hence, the thermal efficiency can be calculated with the following formula:

$$
\eta=\frac{m C_{p}\left(T_{w 2}-T_{w 1}\right)}{A \int I \mathrm{dt}}
$$

where $\eta=$ energy yield; $\mathrm{m}=$ mass of water $(\mathrm{kg}) ; t=$ time $(\mathrm{sec}) ; T_{w 1}=$ initial temperature of water $\left({ }^{\circ} \mathrm{C}\right)$; $T_{w 2}=$ final temperature of water $\left({ }^{\circ} \mathrm{C}\right) ; A=$ collector area $\left(\mathrm{m}^{2}\right) ; \mathrm{I}=$ solar radiation $\left(\frac{\mathrm{W}}{\mathrm{m}^{2}}\right)$.

The Equation (1) is calculated under the standard ASAE S580 [22].

\subsubsection{Water-Heating Module}

The collector performance test was performed under steady-state conditions, with steady radiant energy falling on the collector surface, a steady fluid flow rate and constant wind speed and ambient temperature. When a constant inlet fluid temperature was supplied to the collector, it was possible to maintain a constant outlet fluid temperature from the collector. In this case, the useful energy gain from the collector was calculated from the energy gained was equal to the change in mass by the specific heat of the water by the change in water temperature. Moreover, the thermal efficiency was obtained by dividing by the energy input.

With the Equation (1) the efficiency instantaneous of the water-heating module was calculated, but not the thermal efficiency net return, because for off-normal incidence angles, the optical efficiency was often difficult to be described analytically, in view of it depends on the actual concentrator geometry, concentrator optics, receiver geometry and receiver optics, which may to differ significantly. As the incident angle of the beam radiation increased, these terms became more complex. Fortunately, the combined effect of these parameters at different incident angles could be accounted for with the incident angle modifier. This was simply a correlation factor to be applied to the efficiency curve and was a function of only the incident angle between the direct solar beam and the outward drawn normal to the aperture plane of the collector. It described how the optical efficiency of the collector changes as the incident angle changes. With the incident angle modifier, the thermal performance of heating-water module was estimated with the following expression [23]:

$$
\eta=c_{1}-c_{2} \frac{T_{w}-T_{a}}{I_{b}}-c_{3} \frac{\left(T_{w}-T_{a}\right)^{2}}{I_{b}}
$$

where $T_{w}=$ initial temperature instantly of the water $\left({ }^{\circ} \mathrm{C}\right) ; T_{a}=$ environment temperature instantly $\left({ }^{\circ} \mathrm{C}\right) ; I_{b}=$ solar direct radiation $\left(\frac{\mathrm{W}}{\mathrm{m}^{2}}\right) ; c_{i} i=1,2,3$; curve-fit constants.

\subsubsection{Food-Cooking Module}

Standard established methodological tools were used to evaluate the functioning of the device developed; in this case, a thermal solar system. Since it includes a cooking system, we decided to employ the norm ASAE S580 [22]. To calculate the yield of cooking module, we applied a methodology reported in the literature for this type of technology [24], which applies Equation (1).

To calculate the heating and cooking periods of the solar cooker module, we used the criteria suggested by [25]. In addition, we conducted an exergetic analysis that is considered directly related to the quality of the available energy. Exergy is defined as the maximum amount of work that can be produced by a system under specific environmental conditions. Thus, this kind of analysis provides an alternative means of evaluating and comparing solar cookers and thermal solar systems. Because exergetic efficiencies represent the temperatures associated with energy transfers from and to, a solar cooker, as well as the amounts of energy transferred, they generate a measure of the approximate ideal 
yield of the apparatus. A system's exergetic yield can be defined as the ratio of the exergy gained by the system (exergy output) to the exergy of the solar radiation (exergy input) [26].

$$
\psi=\frac{\psi_{\text {out }}}{\psi_{\text {in }}}=\frac{m C_{p}\left[\left(T_{w 22}-T_{w 1}\right)-T_{a} \ln \frac{T_{w 2}}{T_{w 1}}\right]}{A I \Delta t\left[1+\frac{1}{3}\left(\frac{T_{a}}{T_{s}}\right)^{4}-\frac{4}{3} \frac{T_{a}}{T_{s}}\right]}
$$

where $\psi_{\text {out }}$ is the exergy output, $\psi_{i n}$ is the exergy input, $T_{a}$ environment temperature and $T_{s}$ is the temperature of the black body associated with the sun. The other variables and measures times period are the same ones that were handled in the document.

To evaluate solar stoves, from the point of thermal sight, apply the ASAE S580 standard [22]. The most important criteria of the protocol are:

- Measurement and recording of average temperature of the water inside the container where the food, temperature, environment and irradiance are cooked at intervals $5 \mathrm{~min}$;

- Strong wind conditions (greater than $2 \mathrm{~m} / \mathrm{s}$ ) for more than $5 \mathrm{~min}$, high variation of insolation $\left(+100 \mathrm{~W} / \mathrm{m}^{2}\right)$, low variation heat stroke $\left(-100 \mathrm{~W} / \mathrm{m}^{2}\right)$ or low temperature environment (below $20^{\circ} \mathrm{C}$ ) the tests are invalidated.

To present the cooking power a graph was made. The temperature difference between the water and the environment was in the $X$ axis. The temperature was measured every 5 min until the water reaches $90^{\circ} \mathrm{C}$. On the $\mathrm{Y}$ axis was the standardized cooking power. The standardized cooking power was calculated with the following expression:

$$
P_{S}=P c \frac{700 \mathrm{~W} / \mathrm{m}^{2}}{I}
$$

where $P_{c}$ is the cooking power and $I$ is the insolation falling on cooker aperture in $\mathrm{W} / \mathrm{m}^{2}$. The Pc can be calculated through

$$
P_{c}=m C_{p} \frac{d T}{d t}
$$

where $m$ is the mass of water, $C_{p}$ is the specific heat of water, $\frac{d T}{d t}$ is the derivative of temperature with respect to time and $\mathrm{T}$ is the water temperature at a given time $t$. Moreover, the linear regression technique is applied. The test is valid if the correlation coefficient is greater than 0.7 . The representative value of the cooking power is when the temperature difference between water and environment is $50{ }^{\circ} \mathrm{C}$. The test was performed by exposing the solar cooker to the sun at 10:00 solar time as the protocol marks. Two thermocouples type $\mathrm{K}$ were used to register the temperature inside and outside of pot. The thermometers have error of $1{ }^{\circ} \mathrm{C}$. The incident radiation was measured with a pyranometer (LP02-LI-19) of $1 \mathrm{w} / \mathrm{m}^{2}$. All experimental parameters, such as water temperature within the pot, ambient temperature, wind speed and solar flux radiation were measured every 5 min until the water reaches $90^{\circ} \mathrm{C}$. The test is repeated in the field until the conditions are met. In the same way is repeated the calculation of thermal and exergetic performance if you do not meet the requirements.

\subsection{Energy Consumption Tests to Identify Needs}

A Survey was used to identify the different energy sources used for cooking and water heating (LPG, electricity, charcoal, firewood, etc.). Additionally a Kitchen Performance Test (KPT) was applied to 35 households. This method has made it possible to obtain an index of specific daily consumption and to determine the amounts of firewood (or other fuels) consumed per family, per person or per standard adult per day (kg/cap/day, $\mathrm{kg} /$ family/day) [27]. While KPTS were originally designed woodburning cookstoves, we employed it to compared conventional stoves (either firewood or LPG) to our solar cooking system. The tests were performed in three communities (Huecato, Santo Tomás and Carapan) in random sample of households where other projects of technological development 
and appropriate technologies were implemented [4,12]. The number of surveys and KPTs applied in the three localities was 35 (10 in Carapan, 8 in Santo Tomas and 17 in Huecato). According to the evaluation of solar resources in the study region (Appendix A), the only particularly unfavorable month in terms of hours of sunlight is July.

\subsubsection{Monitoring the Technology}

Monitoring of the MFSS use in the pilot implementation test was performed with the aid of two measuring instruments. For the cooking module, we chose stove use monitors (SUMs, Figure 2a). The viability os SUMS has been reported in the scientific literature for efficient firewood stoves [28] and has also been proposed for solar cookers [29]. SUMs have measurement error of $\pm 0.5{ }^{\circ} \mathrm{C}$. For the water-heating module, a liquid flowmeter sensor was used in association with the electronic arrangement in Arduino (Figure $2 \mathrm{~b}$ ) whit a measurement error a $\pm 0.1 \mathrm{~kg}$. The SUM makes it possible to determine the frequency of use of the solar cooking system, while the flowmeter records the amount of water that can be discharged from the heating module's tank. In both cases, instruments must be placed in a location suitable for monitoring the use of the apparatus. In our study, SUMs were placed on the access hatch of the pot that holds the food, so that when the devise is used it would detect the internal temperature $\left(50-60{ }^{\circ} \mathrm{C}\right)$, while recording the ambient temperature when not in use $\left(10-35^{\circ} \mathrm{C}\right)$. The flowmeter, in turn, was connected to the hot water output hose to register the amount of water discharged.
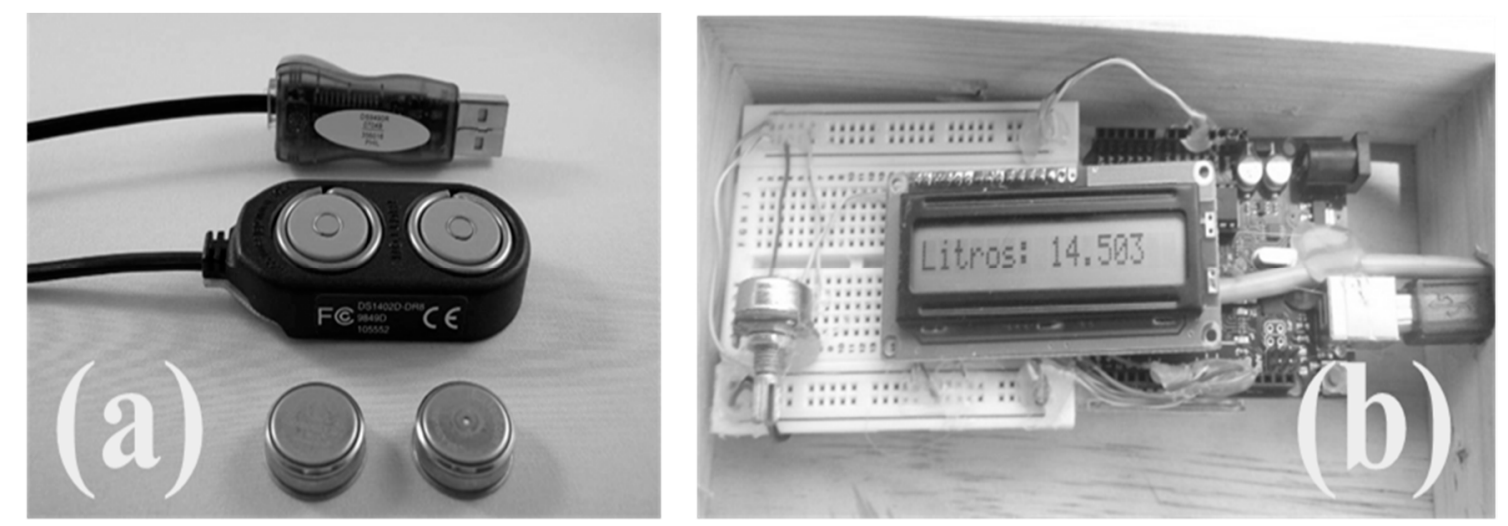

Figure 2. (a) Stove use monitor (SUM) sensors and data recorder; (b) YF-S201 flowmeter with data screen.

\subsubsection{Analysis of the Adoption of the Multifunctional Solar Cooking System}

To determine the use of the technology implemented in this study, we conducted a pilot project. The monitoring time for this analysis was 18 days and took place in five local homes: three in Carapan, one in Santo Tomás and other in Huecato.

The beneficiaries were chosen on the basis of a diagnosis of needs conducted previously. They were then trained in the use and maintenance of the MFSS. Using the analysis of the temperature patterns recorded by the SUMs installed in the cooking module, we were able to determine the number of times that the system was used. The meteorological conditions during the testing days were favorable for the use of the MFSS.

Below is a schematic summary to show the methodology that was followed throughout the process (Figure 3). 


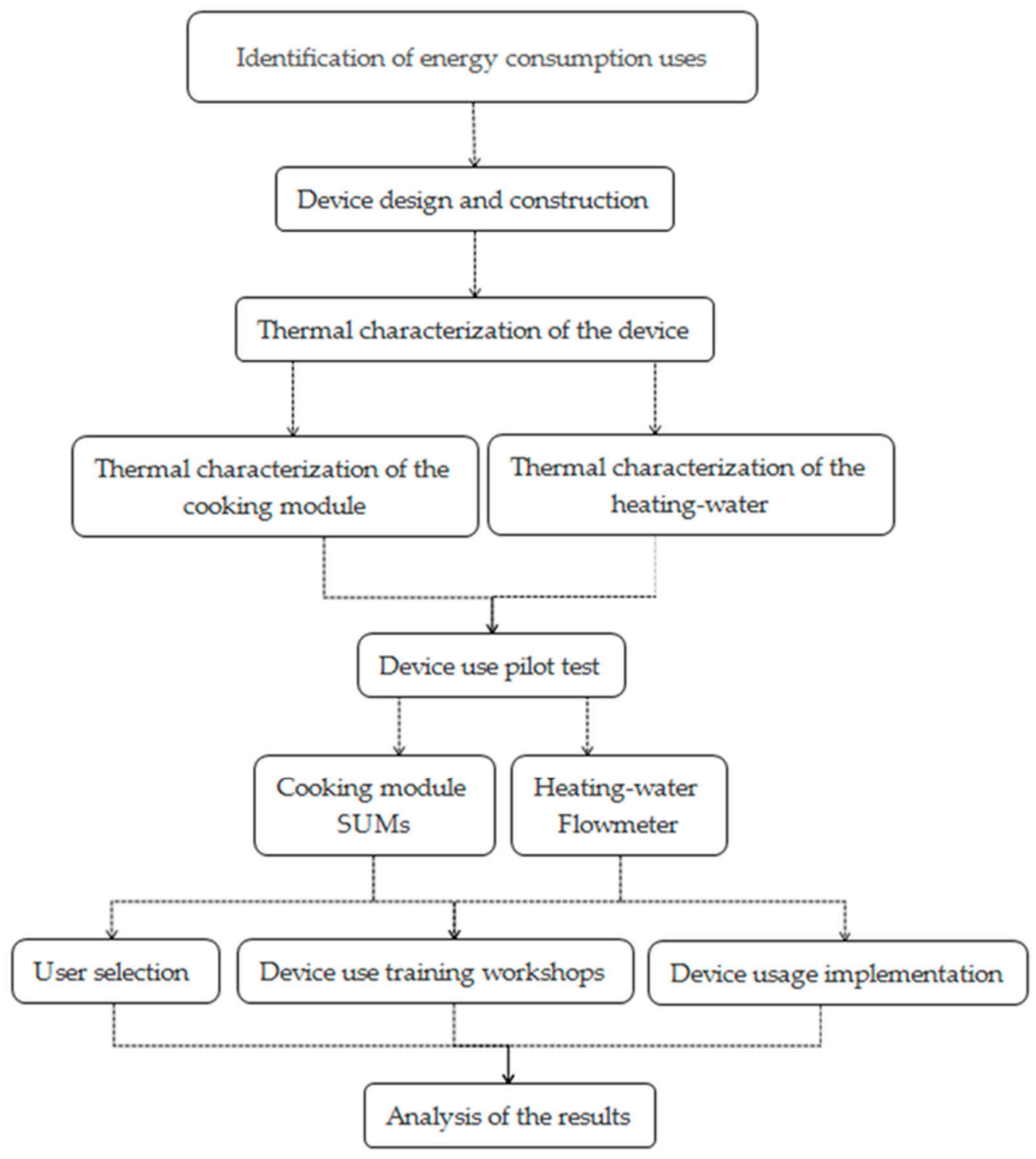

Figure 3. Methodology.

To carry out this work, it was necessary to develop and integrated intervention methodology. First we needed to contact the inhabitants of the communities and, convincing them to accept the implementation of the devices. We then identified potential users using a questionnaire on energy uses and tasks, and trained users on the correct operation of the device, (in some cases it was necessary and do it in their native language). Finding the correct placement for the SUMs was not a trivial task and a variant of the design considered in previous work was taken [15].

\section{Results}

\subsection{Evaluation of the Functionality of the Technology}

\subsubsection{Thermal Analysis of the Water-Heating Module}

Thermal yield is a function of the difference between the temperature of the water and the ambient temperature of the solar water-heating module. To find the thermal performance of the water heater module, the data of the temperature difference of the heater was plotted against the performance thermal. To obtain the performance thermal, was used the formula energy output divided by the energy input Equation (1). 
By graphing the data recorded during experimentation it was obtained average yield is approximately $50 \%$ (Figure 4 ).

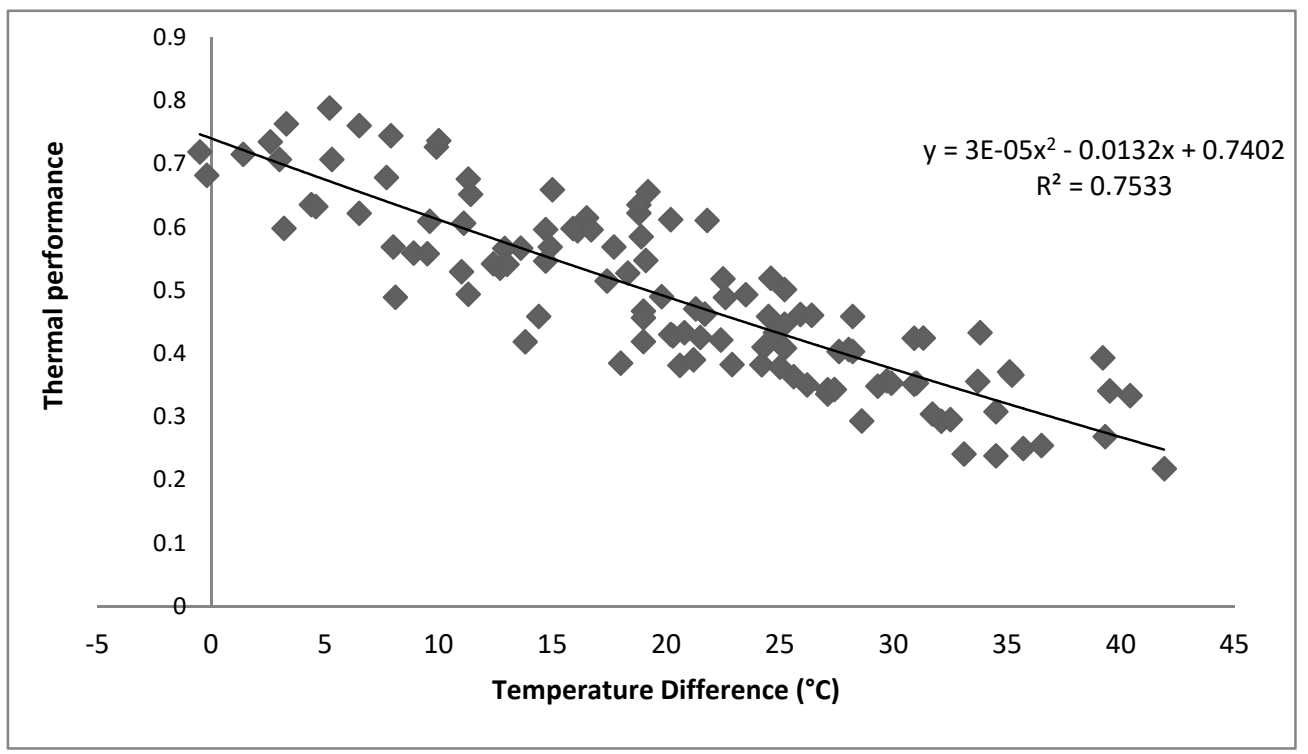

Figure 4. Thermal yield of the solar water-heating module.

In the graphic it can be observed polynomial regression line reveals a correlation coefficient above 0.75 this means that if there is a reliable correlation. Moreover, he most important, the expression for the instantaneous thermal performance is according the Equation (2) with the quadratic adjustment of the data obtained experimentally in the field, whit $c_{1}=0.74, c_{2}=0.013$ and $c_{3}=0.00003$. The expression is given by:

$$
\eta=0.74-0.013 \frac{T_{w}-T_{a}}{I_{b}}+0.00003 \frac{\left(T_{w}-T_{a}\right)^{2}}{I_{b}} .
$$

Thermal yield obtained is similar to that to typical solar water heaters with flat plates or evacuated tubes. Figure 5 shows an example (only once day) of how the water temperature increases in heating-water module. Later you will notice that it is different from the solar cooking module. The temperature maximum that heating-water module is $60^{\circ} \mathrm{C}$, this temperature is approximate to $\pm 55^{\circ} \mathrm{C}$, which is to say, similar to the established Mexican standards to prevent burning users in solar heaters [29].

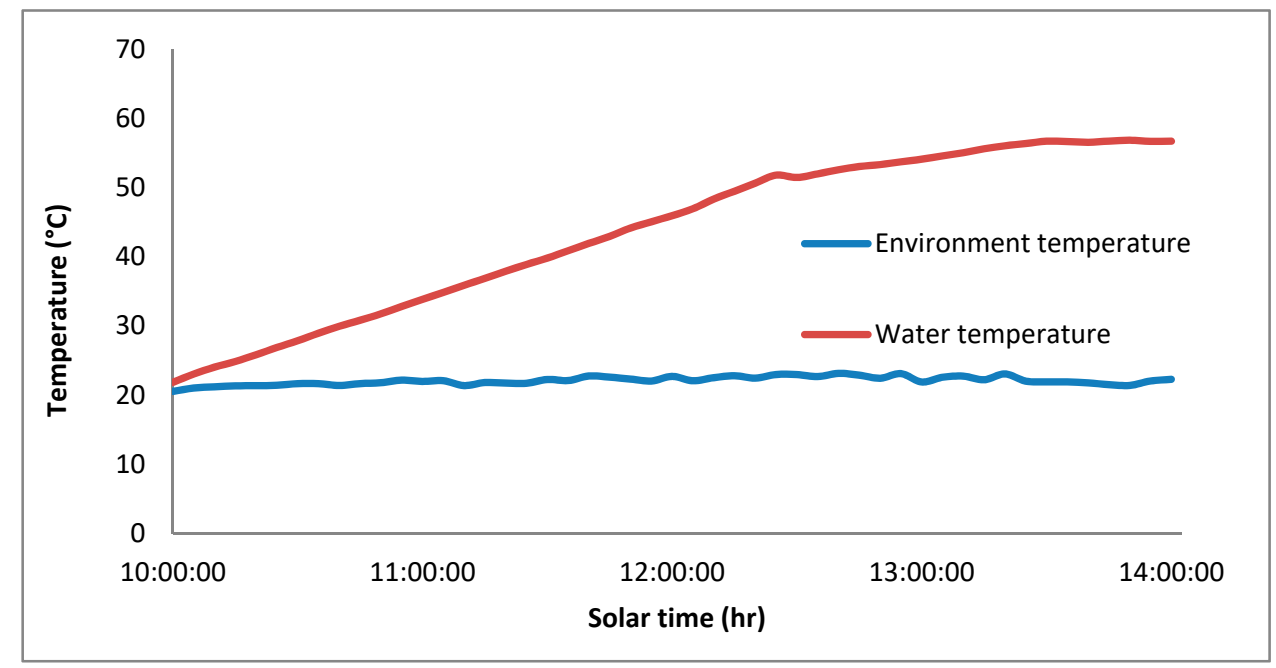

Figure 5. Water temperature in heating-water module. 


\subsubsection{Thermal Analysis of the Solar Cooking Module}

When applying the norm ASAE S580 to the solar cooking module, that is to say, the Equations (4) and (5) the standard cooking power and graph the data, the Cooking Power is approximately 150 watts (Figure 6).

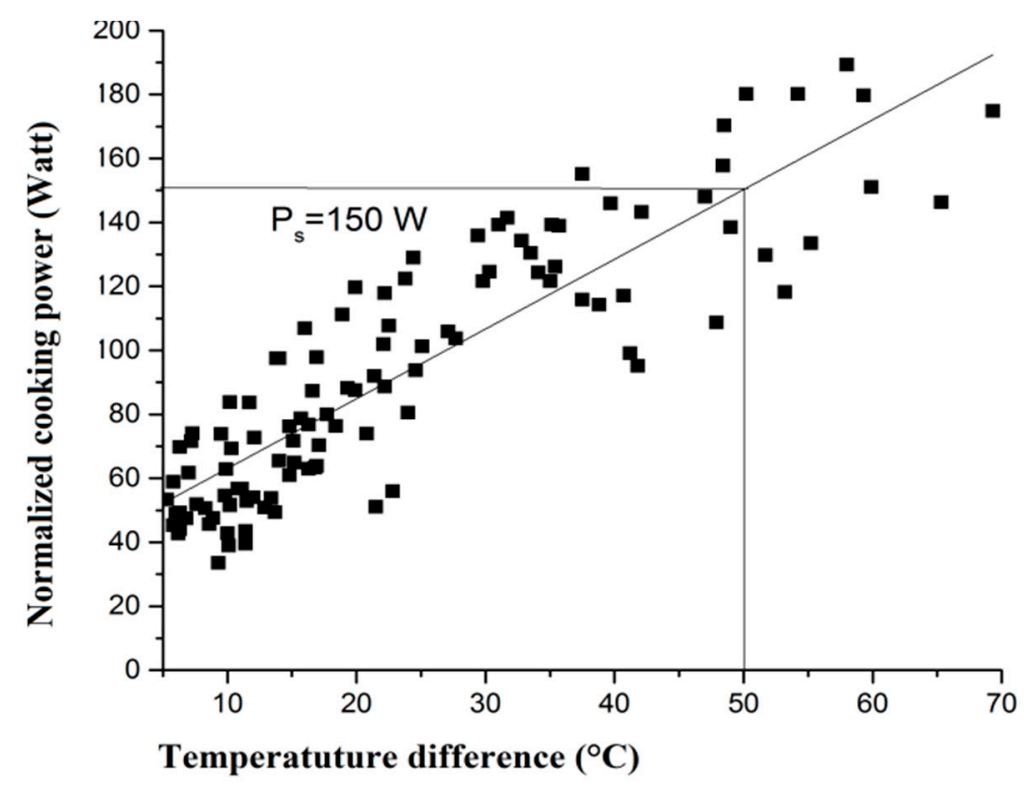

Figure 6. Experimental data to determine standard cooking power.

To calculate the derivative of temperature with respect to time, we use the three-point progressive formula (Appendix B). The adjustment line has a correlation coefficient of 0.9 and error of \pm 4 watts. Here, the obtained experimental error has determined to be $\sim 10 \%$.

It should be noted that the linear regression curve has a positive slope, which is unusual for the slopes associated with the cooking powers of solar stoves. In general, the slopes are negative, the cooking power decreases when the temperature difference increases. To analyze in more detail, the thermal and exergy performance was considered on function on the temperature difference. (Figure 7) shows the thermal performance as a function of the temperature difference, also showing an unusual positive slope.

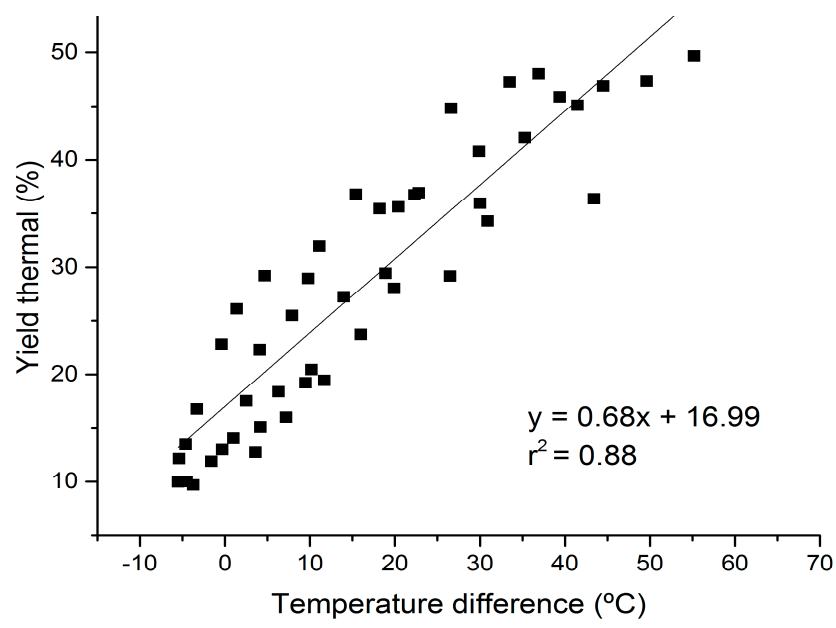

Figure 7. Linear regression curve of the thermal yield has a positive slope. 
In the same way, the exergetic performance was plotted as a function of the temperature difference (Figure 8).

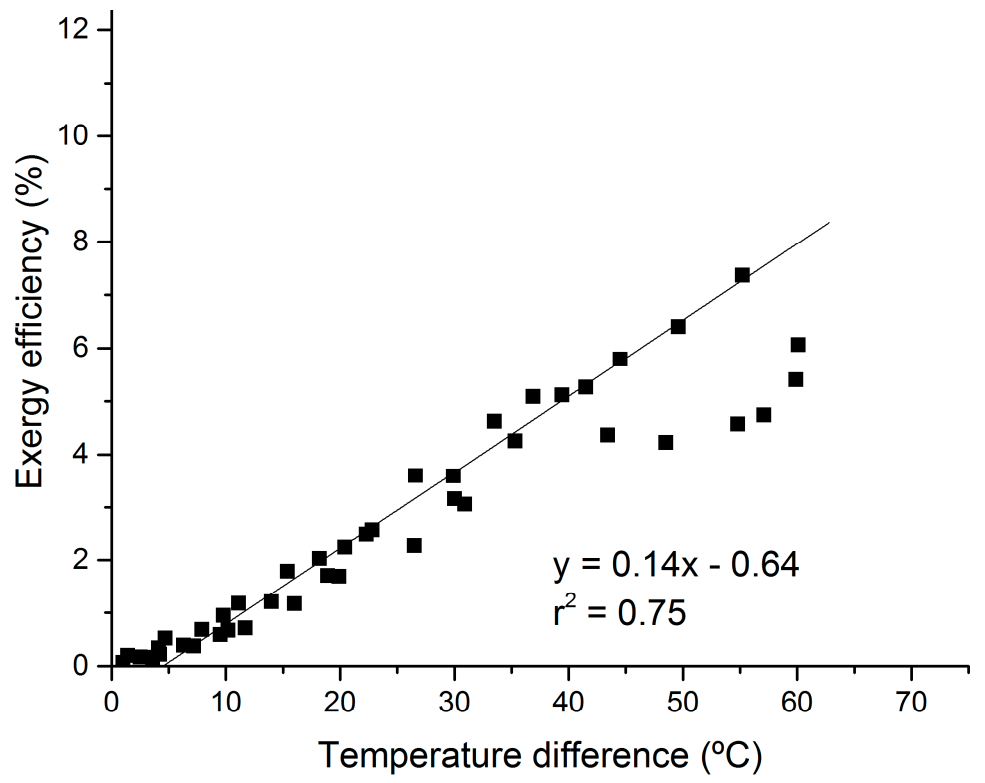

Figure 8. Linear regression curve of the exergetic yield has a positive slope.

(Figure 9) shows the water temperature profile as a function of time, during the duration of the test to obtain the thermal parameters. It can be noted that water mass of $5 \mathrm{~kg}$, reaches the boiling point approximately on 2 hours and $45 \mathrm{~min}$.

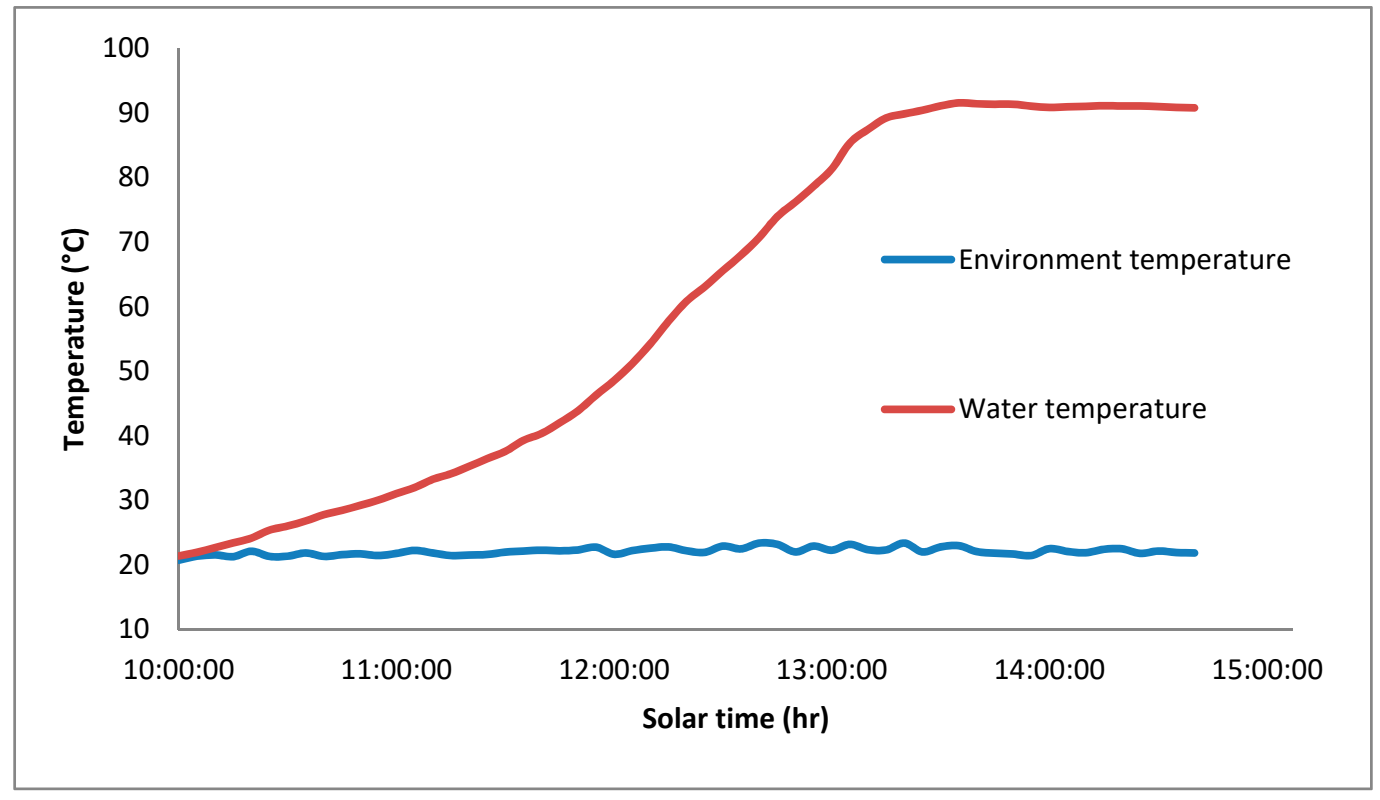

Figure 9. Water temperature in food cooking module.

For the cooking module we also calculated thermal yield, which turned out to be $19 \%$ and exergetic yield, which was $11 \%$. The uncertainty for the measurements of yields was $\pm 2 \%$ and $\pm 1.5 \%$, respectively. The time period for heating the cooking module was $3 \mathrm{hrs}$.

The results for the cooking module show unusual behavior in the adjustment curves, as they have? (form) positive slopes for standard cooking power, thermal and exergetic yield, (unusual assuming they were separately solar stoves or water heaters). To explain this phenomenon, we make two conjectures. 
First, since it is a single device with two modules as shown in Figure 1, the water-heating module receives radiation more directly before the solar midday, while the cooking module receives it after solar midday, therefore the increase temperature of water in cooking module was higher than expected.

Second, once the temperature in the solar heater module increases, this transfers heat to the food cooking module and this one at the same time exchange heat to the solar heater, this transfer was not taken into account for the presentation graphic. Moreover, although the objective of this study was the development of the device and the examination of the adoption process, a study of heat transfer between both modules would be needed to explain the thermal? more accurately.

\subsubsection{Multifunctional Solar Cooking System}

The results of the two energy diagnoses were processed separately. The survey on household energy consumption generated qualitative results on families' end uses and cooking tasks by the type of fuel employed, as follows.

- The households surveyed depend primarily on firewood, followed by LPG;

- The main end-uses that require energy were cooking food and heating water.

- Regarding the use of fuels for cooking tasks and heating water, $54.5 \%$ of the families surveyed responded that they use only firewood, while only 3.6\% indicated that they used LPG for these two purposes;

- In $22 \%$ of homes, both fuels-firewood and LPG are used simultaneously for cooking. Firewood is the fuel used most often used to heat water (58.2\%), while $27.3 \%$ use LPG and $12.7 \%$ utilized other fuels to satisfy this need;

- In summary, $94.5 \%$ of all families surveyed use firewood to satisfy their basic energy needs, in particular, cooking of food and heating of water.

The cooking module was assumed to be in use when the temperature peaks surpassed $49^{\circ} \mathrm{C}$. However, in both graphs (Figure 10), temperature peaks can be seen in the range of $36-49^{\circ} \mathrm{C}$. If these were cases of non-use, those temperature peaks would surpass the ambient temperature at the testing site and contradict the testimony of the users involved. Thus, it is possible to infer that water was extracted from the storage tank, which was then refilled with cold water, as this would reduce the ambient temperature inside the apparatus and indicate that the device's cooking module was in use.

To demonstrate this inference, we compared the use data from the community of Huecato-measured by the flowmeter-and the temperature patterns from the SUM placed in that same system. The 63.2 liters of water discharged from the system as registered by the flowmeter coincided with the seven occasions of use inferred from the data recorded by the SUM. The temperature peaks registered in the range of approximately $36-49{ }^{\circ} \mathrm{C}$ indicate that both the water-heating and food-cooking modules of the device were used. The temperature peaks below $36^{\circ} \mathrm{C}$, meanwhile, indicate that the multifunctional system was not in use since the peaks correspond to the recordings of ambient temperature. Therefore, in both cases the cooking module was used a total of 10 times in this case.

Figure 10 shows the temperature patterns obtained. It was observed that inside the MFSS when the device is charged, the water and food hot, the ambient temperature between the collector and the containers remained in the range approximately $49-60{ }^{\circ} \mathrm{C}$. However, outside the device the ambient temperature is normal.

As a result of these findings, we found that it is possible to determine the use of the solar cooking module and to infer the use of the water-heating module based on the temperature patterns registered by the SUMs. 


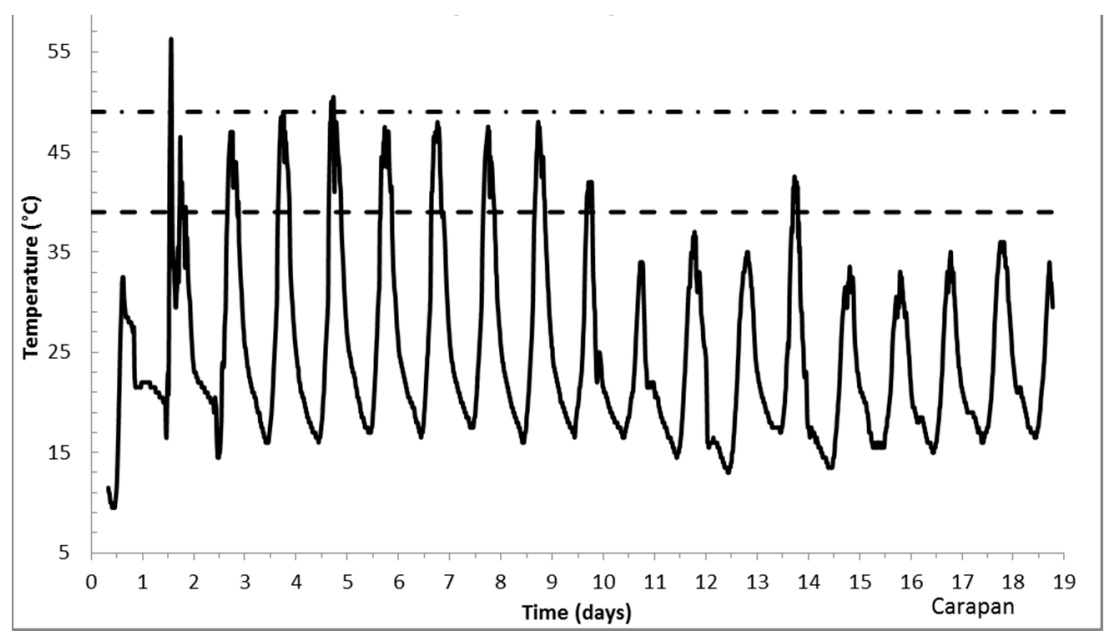

(a)

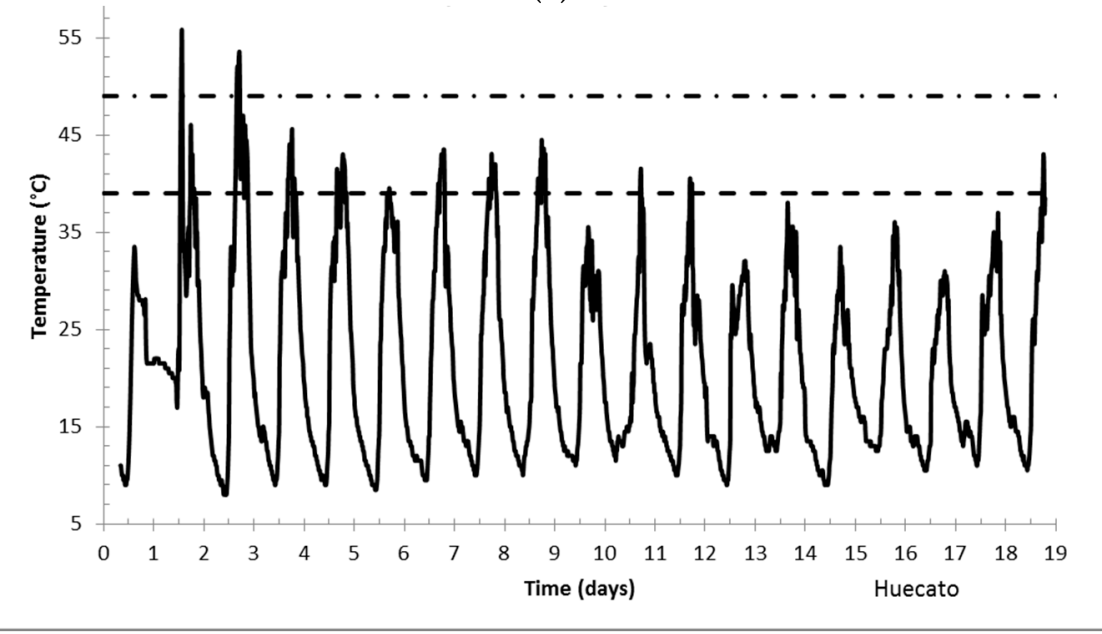

(b)

Figure 10. Temperature patterns recorded in Carapan (a) and Huecato (b). Peaks above the dashed line represent the case of the use of both modules; temperature peaks above the dotted/dashed line represent the use of the cooking module only.

\section{Discussion}

In addition to its innovative design, the MFSS T'imani produced very good results in terms of functionality, as reflected in its thermal performance. In the case of the food-cooking module, standard cooking power turned out to be 150 watts, thermal yield was $19 \%$, exergetic yield was $11 \%$ and cooking time was approximately three hours. The water-heating module, in turn, presented a mean thermal yield above $50 \%$, which is considered very good, with respect to conventional devices for water heating use.

The cooking module showed a somewhat peculiar thermal performance, with a positive slope in the linear regression line for standard cooking power, thermal and exergetic yield, which is unusual in this type of devices. This may be explained by the presence of the water-heating module, but demonstrating this hypothesis will require additional, more detailed, studies designed to establish a more robust explanation.

Regarding the potential use of T'imani MFSS according to our calculations of the availability of solar resources in the region of implementation, it could be used optimally during at least seven months of the year, while in the other five months it could be used to heat water and preheat and reheat foods.

In terms of the stove adoption and monitoring, the data on the use of the solar cooking systems provided objective indicators thanks to our use of the flowmeter and the SUMs. The monitoring 
methodology that involves placing SUMs on the apparatus allows researchers to determine the use of the cooking module and, moreover, to infer the use of the water-heating module, based on analyzing the temperature patterns registered.

During pilot monitoring period, our study determined that the water-heating and food-cooking modules were used $40 \%$ and $60 \%$, respectively. These results could mean significant savings in fuel consumption and important reductions in $\mathrm{CO}_{2}$ emissions while also decreasing the forest degradation generated by the use of wood-based fuels in specific regions. The T'inami MFSS could then provide a versatile device that could complement other efforts directed to reduce the excessive use of fuelwood resources, such as improved woodburning cookstoves.

In addition, it is feasible to implement the T'imani MFSS in many places in Mexico due to its functionality and the abundant country solar resources.

\section{Conclusions}

There are few international publications that address in an integrated manner the development, implementation and adoption of solar thermal technologies for cooking and water heating in rural homes of developing countries. In this research it was hard, but possible to address these different steps. We attribute this success to the fact that the research team is mostly made up of scientists and student from local communities. We found that, in a pilot project, the MFSS device had a good acceptance and thus should result in tangible health, environmental and economic benefits, particularly if promoted together with other alternatives to make a more sustainable use of local wood resources such as improved woodburning cookstoves. However, more extensive studies are necessary, especially regarding the adoption process. Hopefully, this research promotes and catalyzes the implementation of more adoption studies about solar thermal technologies in rural energy stings of developing countries.

Author Contributions: Conceptualization, M.G.-A. and O.M.; data curation, J.Á.R.M. and M.G.-A.; formal analysis, J.Á.R.M. and M.G.-A.; funding acquisition, M.G.-A. and O.M.; investigation, J.Á.R.M.; methodology, M.G.-A. and H.S.C.; project administration, M.G.-A., H.S.C. and O.M.; resources, M.G.-A.; software, J.Á.R.M. and M.G.-A.; supervision, M.G.-A. and O.M.; validation, M.G.-A., H.S.C. and O.M.; visualization, H.S.C.; writing-original draft, J.Á.R.M., M.G.-A. and H.S.C.; writing—review \& editing, J.Á.R.M., M.G.-A., H.S.C. and O.M. All authors have read and agree to the published version of the manuscript.

Funding: This research was funded by CONACyT México, Grant Number 247719 and postdoctoral fellowship. The APC was funded by Mauricio González-Avilés and Omar Masera. Programa para el Desarrollo Profesional Docente para el Tipo Superior (PRODEP).

Acknowledgments: The authors thank Mexico's Consejo Nacional de Ciencia y Tecnología (CONACyT, National Science and Technology Council) for granting post-doctoral scholarships and funding project number 247719, the Universidad Intercultural Indígena de Michoacan, the Instituto de Investigaciones de Ecosistemas y Sustentabilidad of the UNAM (Universidad Nacional Autónoma de México), the Universidad Pedagógica Nacional campus Ichán and the communities of Carapan, Tanaquillo, Huecato, Santo Tomas and Nuevo Morelos. Programa para el Desarrollo Profesional Docente para el Tipo Superior (PRODEP).

Conflicts of Interest: The authors declare no conflicts of interest.

\section{Appendix A}

Evaluation of solar resource in the study region: A preliminary evaluation of the mean solar resources in the study region was performed to validate-together with the standard evaluative tests-the apparatus' functionality (Figure 1). Results are shown in Table A1. The methodology applied to determine the solar resources is reported in [30]. For the case of Mexico, information available in the scientific literature was also incorporated in the analysis [31]. 
Table A1. Evaluation of monthly solar resources in the Cañada de los 11 Pueblos, Michoacan, Mexico.

\begin{tabular}{|c|c|c|c|c|c|c|c|}
\hline Month & $\begin{array}{l}\text { No. of Days } \\
\text { in the Month }\end{array}$ & $\begin{array}{l}\text { Maximum Monthly Hours } \\
\text { of Sunlight (N) }\end{array}$ & $\begin{array}{l}\text { Radiation with Open Sky }\left(\overline{H_{c}}\right) \\
\frac{k J}{m^{2} \text { dia }}\end{array}$ & $\begin{array}{c}\text { Total Radiation }(H) \\
\frac{k J}{m^{2} d i a}\end{array}$ & Hours of Sunlight, Monthly $(n)$ & $\begin{array}{l}\text { Percentage of Hours of } \\
\text { Sunlight, Monthly (\%) }\end{array}$ & $\begin{array}{c}\text { Mean Daily } \\
\text { Hours of Sunlight }\end{array}$ \\
\hline January & 31 & 339.54 & 26,940 & 15,300 & 121.49 & 35.78 & 3.92 \\
\hline February & 28 & 318.39 & 31,103 & 17,700 & 115.10 & 36.15 & 4.11 \\
\hline March & 31 & 368.43 & 35,336 & 19,500 & 121.30 & 32.93 & 3.91 \\
\hline April & 30 & 373.59 & 38,723 & 21,300 & 122.34 & 32.75 & 4.08 \\
\hline May & 31 & 400.88 & 38,916 & 22,100 & 142.51 & 35.55 & 4.60 \\
\hline June & 30 & 395.06 & 39,182 & 18,900 & 85.37 & 21.61 & 2.85 \\
\hline July & 31 & 404.91 & 38,927 & 18,000 & 73.86 & 18.24 & 2.38 \\
\hline August & 31 & 392.28 & 37,905 & 18,300 & 84.88 & 21.64 & 2.74 \\
\hline September & 30 & 363.17 & 35,391 & 17,500 & 85.43 & 23.52 & 2.85 \\
\hline October & 31 & 357.67 & 32,273 & 16,200 & 89.48 & 25.02 & 2.89 \\
\hline November & 30 & 331.86 & 27,947 & 15,600 & 112.50 & 33.90 & 3.75 \\
\hline December & 31 & 335.84 & 25,662 & 13,500 & 96.38 & 28.70 & 3.11 \\
\hline
\end{tabular}




\section{Appendix B}

Three-point progressive formula to calculate the derivative [32]: for the first point:

$$
\frac{d T}{d t} \approx \frac{-3 T_{i}+4 T_{i+1}-T_{i+2}}{2 \Delta t}
$$

for the second and center points:

$$
\frac{d T}{d t} \approx \frac{T_{i+1}-T_{i-1}}{2 \Delta x}
$$

and the last point:

$$
\frac{d T}{d t} \approx \frac{T_{i-2}-4 T_{i-1}+3 T_{i}}{2 \Delta t}
$$

These expressions are used to calculate the cooking power, equation (4). Where $\frac{d T}{d t}$ is the derivative of temperature respect to time. Next is substituted in equation (5) for standardized cooking power.

\begin{tabular}{|c|c|c|c|}
\hline Time (Min) & $\mathrm{T}-\mathrm{H}_{2} \mathrm{O}$ pot $\left({ }^{\circ} \mathrm{C}\right)$ & $\mathrm{I}\left(\mathrm{W} / \mathrm{m}^{2}\right)$ & $P_{s}(W)$ \\
\hline 0 & 18.8 & 968 & 87.6899504 \\
\hline 5 & 20.7 & 979 & 101.574776 \\
\hline 10 & 22.9 & 990 & 100.806821 \\
\hline 15 & 24.8 & 994 & 107.478685 \\
\hline 20 & 27.3 & 1003 & 114.291692 \\
\hline 25 & 29.5 & 1003 & 113.443411 \\
\hline 30 & 32 & 1018 & 143.075558 \\
\hline 35 & 34.8 & 789 & 143.23409 \\
\hline 40 & 37.3 & 1016 & 132.607638 \\
\hline 45 & 40.4 & 1044 & 147.607205 \\
\hline 50 & 43.6 & 1038 & 152.806908 \\
\hline 55 & 46.9 & 1037 & 171.945373 \\
\hline 60 & 50.9 & 1034 & 170.000387 \\
\hline 65 & 54.1 & 1032 & 174.216667 \\
\hline 70 & 58.3 & 1040 & 197.82236 \\
\hline 75 & 62.6 & 1056 & 193.190759 \\
\hline 80 & 66.7 & 1065 & 193.281887 \\
\hline 85 & 71 & 1055 & 199.104762 \\
\hline 90 & 75.3 & 1052 & 203.445434 \\
\hline 95 & 79.8 & 1058 & 185.919644 \\
\hline 100 & 83.3 & 1041 & 268.15376 \\
\hline
\end{tabular}
Table A2 shows the data.

Table A2. Experimental measures to calculate standardized cooking power.

\section{References}

1. Díaz, R.; Berrueta, V.; Masera, O. Estufas de Leña; Red Mexicana de Bioenergía, A.C.: Morelia, Mexico, 2011.

2. FAO. Evaluación de los Recursos Forestales Mundiales 2015; Segunda, Ed.; Organización de las Naciones Unidas para la Alimentación y la Agricultura: Roma, Italy, 2016.

3. CEPAL, N.U. Informe Nacional de Monitoreo de la Eficiencia Energética de México, 2018; Comisión Económica para América Latina y el Caribe (CEPAL): Ciudad de México, Mexico, 2018. 
4. Masera, O.R.; Díaz, R.; Berrueta, V. From Cookstoves to Cooking Systems: The Integrated Program on Sustainable Household Energy Use in Mexico. Energy Sustain. Dev. 2005, 9, 25-36. [CrossRef]

5. Caballero, M. La verdadera cosecha maderable en México. Rev. Mex. Cienc. For. 2010, 1, 5-16.

6. Ghilardi, A.; Guerrero, G.; Masera, O. Spatial analysis of residential fuelwood supply and demand patterns in Mexico using the WISDOM approach. Biomass Bioenergy 2007, 31, 475-491. [CrossRef]

7. SCI. Safe water and Solar Cookers. In SOLAR COOKER REVIEW; SCI: Sacramento, CA, USA, 2013; Volume 19.

8. SCI. Solar Cookers International. 2016. Available online: http://www.solarcookers.org/index.php (accessed on 12 May 2020).

9. Solar Inti. Solar Inti Argentina. 2016. Available online: http://solarinti.blogspot.com.es/ (accessed on 12 May 2020).

10. Inti Illimani. Asociación Inti Illimani. 2016. Available online: https://asointiillimani.wordpress.com (accessed on 12 May 2020).

11. Anti Arequipa. 2016. Available online: https://intiarequipa.wordpress.com (accessed on 12 May 2020).

12. González-Avilés, M.; López-Sosa, L.B.; Servín-Campuzano, H.; González-Pérez, D. Adoption of sustainable technology of solar cookers in indigenous and rural communities of Michoacán. Rev. Mex. Ing. Quim. 2017, $17,273-282$.

13. GTZ. Here Comes the Sun: Options for Using Solar Cookers in Developing Countries; HERA-Household Energy Programme: Eschborn, Germany, 2007.

14. Servín, H.; Peña, M.; Sobral, H.; González, M. Thermal and optical analysis of selective absorber coatings based on soot for applications in solar cookers. J. Phys. Conf. Ser. 2017, 792, 012095. [CrossRef]

15. González-Avilés, M.; Urrieta, O.R.; Ruiz, I.; Masera, O. Design, manufacturing, thermal characterization of a solar cooker with compound parabolic concentrator and assessment of an integrated stove using a monitoring mechanism. Energy Sustain. Dev. 2018, 45, 135-141. [CrossRef]

16. López-Sosa, L.B.; González-Avilés, M.; Hernández-Ramírez, L.M.; Medina-Flores, A.; López-Luke, T.; Bravo-Sánchez, M.; Zárate-Medina, J. Ecological solar absorber coating: A proposal for the use of residual biomass and recycled materials for energy conversion. Sol. Energy 2020, 202, 238-248. [CrossRef]

17. Badran, A.A.; Yousef, I.A.; Joudeh, N.K.; Al Hamad, R.; Halawa, H.; Hassouneh, H.K. Portable solar cooker and water heater. Energy Convers. Manag. 2010, 51, 1605-1609. [CrossRef]

18. Grupp, M.; Balmer, M.; Beall, B.; Bergler, H.; Cieslok, J.; Hancock, D.; Schröder, G. On-line recording of solar cooker use rate by a novel metering device: Prototype description and experimental verification of output data. Sol. Energy 2009, 83, 276-279. [CrossRef]

19. Rabl, A. Comparison of solar concentrators. Sol Energy 1976, 18, 93-111. [CrossRef]

20. Bauer, G. Evaluation of usage and fuel savings of solar ovens in Nicaragua. Energy Policy 2016, 97, $250-257$. [CrossRef]

21. Rabl, A. Optical and thermal properties of compound parabolic concentrators. SPIE Milest. Ser. 1993, 54, 229-243.

22. ASAE, S. Testing and Reporting Solar Cooker Performance. ASAE 2003, 1, 824-826.

23. Kalogirou, S.A. Solar Energy Engineering: Processes and Systems; Academic Press: Cambridge, MA, USA, 2013.

24. Kundapur, A.; Sudhir, C.V. Proposal for new world standard for testing solar cookers. Int. J. Eng. Sci. Technol. 2009, 4, 272-281.

25. Pejack, E. Technology of Solar Cooking. Available online: http//solarcooking.org/Pejack-on-solar-cookertechnology.pdf (accessed on 12 May 2020).

26. Pandey, A.K.; Tyagi, V.V.; Park, S.R.; Tyagi, S.K. Comparative experimental study of solar cookers using exergy analysis. J. Therm. Anal. Calorim. 2011, 109, 425-431. [CrossRef]

27. Bailis, R.; Smith, K.R.; Edwards, R. Kitchen Performance Test (KPT); Univerisity of California: Berkeley, CA, USA, 2007.

28. Ruiz-Mercado, I.; Canuz, E.; Smith, K.R. Temperature dataloggers as stove use monitors (SUMs): Field methods and signal analysis. Biomass Bioenergy 2012, 47, 459-468. [CrossRef]

29. PROY-NOM-027-ENER/SCFI-2016. Proyecto de la Norma oficial para Calentadores Solares de Agua., Diario Oficial de la Federación. Ciudad de México, a 14 de julio de 2016.

30. Duffie, J.A.; Beckman, W.A.; Blair, N. Solar Engineering of Thermal Processes, Photovoltaics and Wind; John Wiley \& Sons: Hoboken, NJ, USA, 2020. 
31. Estrada-Cajigal, V.; Almanza, R. Irradiaciones global, directa y difusa, en superficies horizontales e inclinadas, así como irradiación directa normal, en la República Mexicana. Ser. Inst. Ing. 2005, 646.

32. Burden, R.L.; Faires, J.D. Numerical Analysis-Theory and Applications; Cengage Learning, India Edition; IntechOpen: New Delhi, India, 2009.

(C) 2020 by the authors. Licensee MDPI, Basel, Switzerland. This article is an open access article distributed under the terms and conditions of the Creative Commons Attribution (CC BY) license (http://creativecommons.org/licenses/by/4.0/). 